\title{
VISIBILIDADES DO TRABALHO DE MULHERES RURAIS NA REDE SOCIAL DIGITAL FACEBOOK
}

\author{
Naira Leticia Giongo Mendes Pinheiro \\ Maria Simone Vione Schwengber
}

\section{Resumo}

Entendemos que as redes sociais lançam novas formas de visibilidade a partir de uma existência-virtual nas redes sociais, que permitem compor novas formas de posições de sujeitos. Este artigo objetiva analisar algumas publicações de mulheres rurais na rede social digital Facebook, tomando-as como memórias do tempo presente. Perguntamos: Que publicações são essas e o que produzem? Trata-se de uma pesquisa de caráter netnográfico, estratégica metodológica escolhida como ponte de acesso aos discursos das mulheres permitindo, consequentemente, maior compreensão do mapeamento, das produções, distribuição das publicações. Escolhemos a análise do discurso na perspectiva foucaultiana, mapeando a materialidade simbólica na cadeia significante entre discursos e imagens. Observamos que as publicações desse grupo de mulheres rurais rompem o aspecto mudo da cultura de silêncio em relação as experiências de trabalho e as transformam em direção à celebração de um reconhecimento de suas ações laborais, produzindo, assim, uma certa política de visibilidade do trabalho "pesado" na terra.

Palavras-chave: Facebook; mulheres rurais; visibilidade nas redes sociais.

\section{VISIBILITIES OF WORK OF RURAL WOMEN IN THE FACEBOOK DIGITAL SOCIAL NETWORK}

\begin{abstract}
We understand that social networks launch new forms of visibility from a virtual existence in social networks, which allow us to compose new forms of subject positions. This article aims to analyze some rural women's publications on the Facebook digital social network, taking them as memories of the present time. What publications are these and what do they produce? This is a research of netnographic character, strategic methodological chosen as a bridge of access to women's discourses allowing, therefore, greater understanding of mapping, productions, distribution of publications. We chose discourse analysis in the Foucaultian perspective, mapping the symbolic materiality in the significant chain between discourses and images. We note that the publications of this group of rural women break the silent aspect of the culture of silence in relation to work experiences and transform them towards the celebration of a recognition of their work actions, thus producing a certain work visibility policy "heavy" on earth.
\end{abstract}

Keywords: Facebook; rural women; visibility on social networks.

\section{VISIBILIDADES DEL TRABAJO DE MUJERES RURALES EN LA RED SOCIAL DIGITAL FACEBOOK}

Resumen

Entendemos que las redes sociales lanzan nuevas formas de visibilidad desde una existencia virtual en las redes sociales, lo que nos permite componer nuevas formas de posiciones de sujeto. Este artículo tiene como objetivo analizar algunas publicaciones de mujeres rurales en la red social digital de Facebook, tomándolas como recuerdos de la actualidad. ¿Qué publicaciones son estas y qué producen? Esta es una investigación de carácter netnográfico, metodológica estratégica elegida como un puente de acceso a los discursos de las mujeres que permite, por lo tanto, una mayor comprensión del mapeo, las producciones y 
la distribución de publicaciones. Elegimos el análisis del discurso en la perspectiva foucaultiana, mapeando la materialidad simbólica en la cadena significativa entre discursos e imágenes. Observamos que las publicaciones de este grupo de mujeres rurales rompen el aspecto silencioso de la cultura del silencio en relación con las experiencias laborales y las transforman hacia la celebración del reconocimiento de sus acciones laborales, produciendo así una cierta política de visibilidad laboral pesado en la tierra.

Palabras clave: Facebook; mujeres rurales; visibilidad en las redes sociales.

\section{INTRODUÇÃO}

Gilles Lipovetsky e Serroy (2010) se referem à inovação e ao crescente universo técnicocientífico que domina o mundo contemporâneo o que definem de uma "cultura-mundo". Os autores definem a época "[...] do cibermundo e da comunicação-mundo" (LIPOVETSKY; SERROY, 2010, p. 14). Assim, percebe-se a partir da reconfiguração das dinâmicas culturais que as tecnologias estão contemporaneamente produzindo mudanças. Para tanto, propomos perceber que tais mudanças implicam também o meio rural brasileiro, por meio da interação compartilhada com o que consome/produz em redes sociais digitais, o que tem contribuído para reconfigurar novos valores, novas formas de socializações, assim como de criação de outros códigos culturais ${ }^{1}$, novos modos de existir e de manifestações de pertença e de participação.

Nesse contexto, temos observado a emergência de novos atores, novas sociabilidade e posições de sujeito. Para Foucault (2010) as posições de sujeito se encontram dispersas nos diversos lugares, nas diversas posições que podem ocupar ou receber a partir da produção de um discurso, nas descontinuidades dos planos de onde falam. Dessa forma, a constituição do sujeito está intimamente relacionada às posições sociais que ele ocupa e/ou pode ocupar.

A segunda década do século XXI é marcada por mudanças nas posições, no que tange às visibilidades e invisibilidades das mulheres rurais, uma vez que enfrentaram dificuldades em ser e se verem representadas dentro do sistema patriarcal brasileiro. Pretendemos, ao longo deste artigo, produzir argumentos para embasar a hipótese de que as mulheres rurais (a partir de acompanhamento de um grupo), por sua experiência social específica, estariam predispostas à situação de visibilidade social por meio de conjunto de publicações nas redes sociais digitais.

Entendemos que este é um fenômeno contemporâneo que tem sido possibilitado pelas tecnologias como as das redes sociais digitais - tal como o Facebook. Assim, nos desafiamos a pensar, neste artigo, o quanto algumas publicações, nas redes sociais digitais de um grupo de mulheres rurais, têm-se constituído como um "capital de visibilidade", no sentido de atribuir valor ao trabalho que realizam na terra. Objetivamos compreender as publicações de um grupo de mulheres rurais na rede social digital Facebook, perguntando: que publicações são essas? Que visibilidade tais publicações produzem?

Sinalizamos a seguir alguns dos elementos conceituais que configuram a coluna argumentativa da pergunta que nos propusemos. A começar pelo entendimento da "visibilidade", a partir da ideia de uma existência-virtual, possibilitada pelos meios técnicos decorridos nas e pelas novas redes sociais digitais, que têm permitido compor novas formas de posições de sujeitos e um novo jeito de existir a partir do ciberespaço. (RECUERO, 2009).

\footnotetext{
${ }^{1}$ Com isso, temos pensado que se altera a noção histórica de rural como lugar "atrasado", para um lugar de certo desenvolvimento integrado.
} 
Há na contemporaneidade diferentes territórios existências ou "espaços-mundos"” entre o ciberespaço das redes sociais digitais, o que produz novos jeitos de existir - a existência-virtual. Não há como negar que as redes sociais têm tomado um espaço considerável na vida das pessoas, cada vez mais vivendo em uma existência-virtual.

A vida social contemporânea é transferida em parte para a vida social em redes digitais. A visibilidade nas redes sociais digitais é convertida num tipo de "capital social relacional", conceito construído ao redor da ideia de que interações sociais possuem um valor atribuído, como destaca Recuero (2009). O capital social se manifesta através de valores como os de reconhecimento, valorização, novas representações.

Desse modo, temos pensado que as redes sociais lançam outros campos de visibilidades para as mulheres, no caso das mulheres rurais. Destacamos os entrecruzamentos e as reestruturações de linguagem proporcionados pelas redes sociais digitais que parecem pôr em operação um redesenho dos modos tradicionais do passado, a partir do estabelecimento de novos modos de existência, de sociabilização, de memória. Assim, tomamos o uso das redes sociais digitais, em especial a rede social digital Facebook, como um suporte de "memórias do presente".

O espaço de memória ocupado historicamente pelas mulheres ao longo da história registra experiências restritas, evidentemente ligadas ao espaço privado (PERROT, 2005). Nesse sentido, o trabalho, geralmente, fundamenta-se numa ideia antagônica entre o trabalho de homens e o trabalho de mulheres, no qual a divisão dos espaços — o privado, habitualmente considerado sem valor como o das mulheres - e o público e produtivo/de renda como dos homens. A memória, como nos ensina Le Goff (2003) e Candau (2012), concebida como um fenômeno construído socialmente e vinculada nas relações de poder, se constitui como objeto de disputa social. A memória das mulheres está, quase sempre, identificada com certos tipos de trabalhos, que reproduzem e direcionam o trabalho nos espaços domésticos. Construiu-se historicamente uma seleção e divisão dos espaços, denominados por um sistema que silenciou por muito tempo o trabalho das mulheres rurais.

A categoria gênero nos ajuda a problematizar as diferenças entre homens e mulheres; discute as dimensões do poder, afirmando gênero como uma "[...] construção sociocultural, produto das relações sociais desenvolvidas no tempo e que se pode, consequentemente, desconstruir" (PERROT, 2005, p. 264). Assim, as mudanças da tecnificação de comunicação possibilitam a emergência de uma nova memória, que Virilio (2006, p. 94) nomeia como "memória do presente", aquela em que os acontecimentos, ao mesmo tempo em que são vividos, são narrados e registrados. As redes digitais têm nos possibilitado expandir nosso olhar para a memória do trabalho das mulheres rurais, contribuindo para distanciá-las de memórias subalternas, que se desdobram das culturas minoritárias, relegadas a posições marginais e de valor menor, em oposição à memória oficial (HALBWACHS, 2006).

Entendemos que as publicações em redes sociais digitais, em certa medida, reconstituem o vivido (cotidiano), o que se situa entre o relato verbal e visual, demostrando o que somos (FOUCAULT, 2013). As publicações constituem memória do presente, pois posicionam publicamente o sujeito e seus modos de subjetivação, rompem "[...] lacres da reminiscência, do esquecimento" (FOUCAULT, 2013, p. 69), atualizam os sentidos, sendo capazes de não só cativar a si (quem posta), mas também de capturar o olhar do outro; almejam uma audiência, buscando um certo reconhecimento, legitimação.

\footnotetext{
${ }^{2} \mathrm{O}$ ciberespaço constituído como rede sociotécnica, que preside um hibridismo entre humano e máquina, entre o/a usuário/a da tela - homo ecranis, de que nos fala Lipovetesky e Serroy (2010). Uma ecologia estruturada "cultura-mundo" que expande as existências em confluência com mídias e tecnologias.
} 
Os registros nas redes sociais digitais, embora pertençam ao escopo da memória individual e sejam eventos e fatos ocorridos com cada de um nós, quando publicizados pertencem a uma memória externa, coletiva, como afirma Halbwachs (2006). É no bojo dessas discussões teóricas que buscamos destacar como, por meio das redes sociais digitais, um grupo de mulheres rurais visibiliza suas posições, destacando a presença de atuações no trabalho com a terra, o que pode contribuir para a reelaboração e/ou reposicionamento identitário. Na seção a seguir apresentamos alguns dos critérios das escolhas metodológicas.

\section{METODOLOGIA}

Este artigo é desdobramento de uma pesquisa anterior denominada Mulheres rurais, cuidado de si e práticas de lazer ${ }^{3}$. Essa pesquisa entrevistou 224 mulheres residentes em assentamentos da reforma agrária e reassentamentos de atingidos por barragens no município de Jóia, no estado do Rio Grande do Sul, sobre suas experiências de lazer. Localizamos um conjunto de experiências de lazer concentradas em: experiências religiosas; ouvir rádio; ver televisão; dormir ou descansar; ir à vizinhança; participar de festas comunitárias e de festas campeiras; uso de tecnologias com acesso à Internet; às redes sociais digitais e, no caso específico, à rede social digital Facebook. Com base nos resultados dessa pesquisa, tomamos como objeto de estudo a rede social digital Facebook, os usos e as publicações feitas por mulheres rurais.

Assim, realizamos uma visita a cada uma delas, ocasião em que procedemos a uma entrevista semiestruturada. Após a entrevista, a transcrevemos na íntegra e fizemos a compilação das informações em ficha catalográfica, usada para construir o perfil das participantes da pesquisa. A partir disso, fizemos um levantamento das mulheres que possuíam conta na rede social digital Facebook, para participação na pesquisa e que fossem usuárias ativas e assíduas na rede social digital, além de se encaixarem em critérios como faixa etária acima de 25 anos, publicações de conteúdos sobre suas atividades como o trabalho com a terra (para que a observação pudesse ser realizada), totalizando 14 mulheres.

A escolha dos dados se deu por meio da análise do discurso - a qual tratamos neste artigo, como discursos das relações de trabalho com a terra. Como ferramenta metodológica utilizamos a netnografia, fazendo uso da captura de informações interativas vindas de pessoas reais. As observações foram feitas mediante nossa inserção na rede, pelo vínculo de amizade com as mulheres entrevistadas, para a captura de telas $\left(\right.$ Print Screens $\left.^{4}\right)$ das publicações realizadas por elas no período que compreendeu o ano de 2013 ao ano de 2017, compondo um corpus analítico de 50 Prints Screens, dos quais $90 \%$ faziam referência ao trabalho com a terra, justificando a escolha dessa categoria analítica.

Para isso, a netnografia nas redes sociais digitais possibilitou um recorte de escolha, sendo ela uma metodologia focal, experimental, observacional e compreensiva, que se reconhece como fruto de uma "negociação construtiva" entre o/a pesquisador/a e o/a pesquisado/a durante relações de observações (AMARAL; NATAL; VIANA, 2008, p. 6). Para tanto o/a pesquisador/a realiza monitoramento prolongado, no caso, das publicações relacionados ao seu objeto de pesquisa, na plataforma de observação. De maneira mais direta, o/a pesquisador/a se refere a alguns movimentos da dinâmica do que chama a popularidade e constância das publicações, pela busca da tessitura que gravita em torno de seus temas. Ressalta-se que as pesquisas consideradas netnográficas são de imersão na rede.

\footnotetext{
${ }^{3}$ Chamada CNPq n. 32/2012.

${ }^{4}$ Print Screen - captura em forma de imagem de tudo o que está na tela do computador, por meio de um clique na tecla com o mesmo nome.
} 
As mulheres observadas utilizam a rede social digital Facebook e costumam acessá-la em vários momentos durante o dia, acumulando um tempo estimado em duas horas diárias. Elas têm idade entre 25 e 62 anos, sendo que uma é divorciada e as demais são casadas. A escolaridade delas varia dos Anos Iniciais do Ensino Fundamental à Pós-Graduação; uma cursou até a $2^{a}$ série; seis delas até a $4^{a}$ série; duas cursaram o Ensino Médio; duas cursaram o Ensino Superior; e duas cursaram Pós-graduação. O tempo de vivência no meio rural é superior a dez anos, sendo que a maioria das mulheres viveu a vida toda nesse espaço. A Internet está presente na vida dessas mulheres há, aproximadamente, oito anos. Nas relações de amizade, as mulheres estudadas têm um número de amigos considerável, variando de 360 a 2257 integrantes. Os contatos são variados, com diferentes graus de relacionamento, como com outras mulheres dos assentamentos, amigos, familiares, pessoas do comércio, instituições religiosas, entre outros.

Do ponto de vista da metodologia adotada, realizamos as análises valendo-nos das contribuições de Foucault (2010) no que tange aos conceitos de discurso e de enunciado. O autor sugere que o/a pesquisador/a situe os enunciados nos domínios do discurso. Em primeiro lugar, enfatiza Foucault (2010, p. 113-114), é preciso considerar que o enunciado se insere em um campo enunciativo, de que "[...] não há enunciado em geral, livre, neutro e independente; mas sempre um enunciado fazendo parte de uma série ou de um conjunto [como peça que] integra sempre um jogo enunciativo". Em segundo, o autor assevera que o enunciado estabelece uma estreita relação com as posições de sujeito e com a memória social.

O desenho metodológico adotado partiu do entendimento das publicações como acontecimento discursivo, desdobrado em enunciados. Nessa perspectiva, uma materialidade emerge nos movimentos de entrecruzamento de enunciados, mais precisamente naqueles observados a partir do trajeto temático que, no recorte desse artigo, foi o trabalho com a terra. Nesse aspecto, o trajeto temático compreende um mecanismo a partir do qual é possível observar as dinâmicas dos enunciados. Esse trajeto conduzirá a articulação e mapeamento do corpus, tensionando suas condições de produção e as posições de sujeito nele descrita. Instrumentalizadas por esse "modo de ver", optamos por mapear, além dos enunciados, as imagens, observando o efeito de afirmação na produção das fotos-imagens. Fotos-imagens de quem busca reafirmar a posição enunciativa.

Observa-se que, nas publicações, as imagens "passam por dentro", comportam o sujeito ordinário, sujeitos que eram "silenciosas e invisíveis" quebram o domínio, apropriam-se da rede social digital Facebook, produzem um espaço de circulação que entra para a ordem do discurso digital.

Assim, analisamos as imagens que, frequentemente, integram os textos das publicações não como peças ilustrativas, mas como prática discursiva. Soares (2002) ensina que as imagens não são independentes, pois estão ligadas a determinados regimes de saber-poder e movimentam significados, induzindo a que se vejam algumas coisas em detrimento de outras. Vivemos um processo de valorização e intensificação das imagens na diversidade de suportes digitais. Como afirma Fischer (2007), a civilização contemporânea vive a imagem; trata-se de uma espécie de corrida da visibilidade, na medida em que as referências para o ser humano são deslocadas e potencializadas pela pulsão da visibilidade midiática.

As imagens são formas de expressão, e pelo acompanhamento vão engrossando o conjunto de versões e de sentidos. Para Foucault (2010), os discursos são recursos de ditos, carregados de sentidos, de vida, se produzem de modo visível (pelas imagens) e dizível. A análise do discurso, no entanto, é um modo que permite observar os sentidos, os rastros de uma memória (FOUCAULT, 2010). Assim, tomamos as imagens como discursos, pois nos permitem a compreensão dos modos de funcionamento dos ditos, os princípios de organização e as formas de produção social dos 
sentidos discursivos (FOUCAULT, 2010). Na concepção de Schwengber (2012, p. 145), os discursos "[...] constroem e implementam significados por meio de procedimentos internos que regulam, classificam, selecionam, incluem e excluem, os quais, por sua vez, produzem e legitimam o que é aceito como verdade em um determinado tempo e lugar”. Para Foucault (2010, p. 8), isso

[...] supõe que em toda sociedade, a produção no discurso é ao mesmo tempo controlada, selecionada, organizada e redistribuída por certo número de procedimentos que têm por função conjurar seus poderes e perigos, dominar seu acontecimento aleatório, esquivar sua pesada e temível materialidade.

Conforme Rago (2013), há que se falar de uma nova história das mulheres, na medida em que perguntamos pelos modos de constituição de si experienciados por elas na rede social digital. Rago (2013) destaca a importância de focalizar a constituição do próprio olhar que as mulheres produzem sobre si mesmas, ampliando as formas de compreender e enxergar o processo de feminização cultural em curso e o aporte social e cultural das mulheres no mundo público, como na rede social digital Facebook.

A partir desses pressupostos teórico-metodológicos analisamos o volume de publicações $a$ priori e escolhemos uma unidade de análise que tematiza o trabalho das mulheres rurais com a terra, na direção de destacar como esse grupo de mulheres, por meio de suas publicações, colaboram para reelaborar as posições das mulheres rurais, tais como: ativas e envolvidas na produção agrícola. As mulheres rurais brasileiras, segundo a Organização das Nações Unidas (2017, s./p.):

[...] são as responsáveis por mais da metade da produção de alimentos do mundo. Elas exercem também um importante papel na preservação da biodiversidade e garantem a soberania e a segurança alimentar ao se dedicar a produzir alimentos saudáveis [...], [mas] [...] são marginalizadas porque apenas 30\% são proprietárias formais de suas terras, $10 \%$ conseguem ter crédito e $5 \%$ recebem assistência técnica.

Sales (2007) defende a ideia de que o trabalho das mulheres, por muito tempo, permaneceu na invisibilidade, mas, os dados e o movimento investigativo apresentado a seguir nos ajudam a pontuar que elas estão produzindo na terra, plantando, colhendo. As mulheres, além de serem as principais responsáveis pelo cuidado com a casa, filhos e o entorno da propriedade, estão envolvidas na produção da terra, embora tenham ainda de lutar arduamente "[...] pelo direito de serem reconhecidas como trabalhadoras, uma vez que são as responsáveis pela grande parte das atividades que caracterizam a pluriatividade na agricultura familiar brasileira" (SALES, 2007, p. 437).

\section{VISIBILIDADES DO TRABALHO DAS MULHERES NA E COM A TERRA}

Destacamos aqui o conjunto de imagens publicizadas na rede social digital Facebook que constrói e posiciona o trabalho das mulheres rurais para quem as vê, seus seguidores, a partir do vínculo de amizade com as mesmas, o que implica o reconhecimento da capacidade de uma produção simbólica por parte das mulheres e a constituição das suas manifestações, representações. Para Jenkins (2009), a principal mudança do modelo de comunicação, do século XX para o século XXI, nos meios digitais, é a participação, passando de espectador passivo até atuante. Trata-se da mudança de uma cultura digital que torna os sujeitos participantes da produção do conteúdo que acessam e consomem.

Segundo Miguel e Boix (2013, p. 47), no contexto da cultura de participação digital, as mulheres vêm abrindo um outro mundo com "[...] uma nova possibilidade, um novo espaço - para 
além ou mais dos espaços privados/domésticos", de modo que as posições tradicionais de gênero têm sido tensionadas. Dessa forma, uma parcela das mulheres rurais tem encontrado, na rede social digital Facebook, um espaço para quebrar alguns dos estereótipos da imagem da mulher, apenas ligada aos afazeres da casa, cultivada nos séculos anteriores. Convidamos à visualização da publicação a seguir.

Figura 1: Print Screen do Facebook

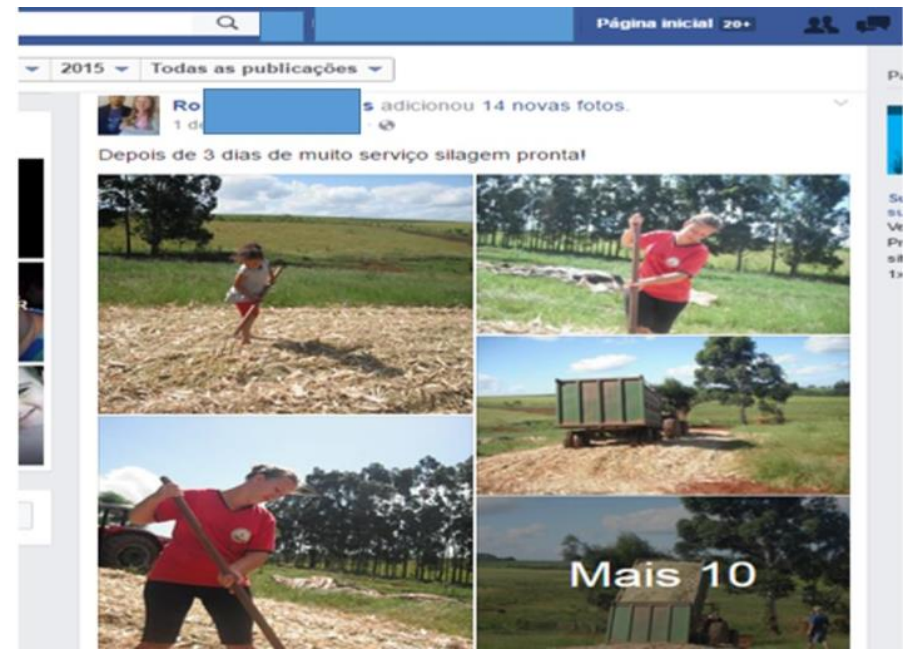

Fonte: Facebook, 2017.

Observando as imagens dessa publicação, identificamos facilmente duas mulheres. A postagem vem acompanhada do seguinte enunciado: "Depois de 3 dias de muito trabalho silagem pronta!" Publicações que registram e mostram ações laborais na terra, envolvidas com a produção agrícola da propriedade. Ao postar, publiciza uma prática discursiva sobre uma legitimação identitária do trabalho com a terra e dá visibilidade às suas ações, alargando os laços sociais que, segundo Pereira (2016), se mantêm por meio de uma rede nas curtidas e/ou comentários ${ }^{5}$ e, ainda, compartilhamentos.

Para Foucault (2010), as práticas discursivas têm como foco os processos de produção, de distribuição, de consumo discursivo textual, visual. As imagens publicadas por elas parecem não ser meros "sinais" - correspondem a compostos simbólicos que ajudam a fixar noções em materialidades significantes perceptíveis e comunicáveis, pois se inscrevem em códigos convencionais partilhados por determinadas comunidades. As imagens, longe de apenas "presentificar" a realidade, são instrumentos de simbolização que extraem suas forças exatamente do "efeito-prova" ou "efeito-síntese" das significações existenciais construídas (CARVALHO, 1999, p. 51), como podemos ver na figura a seguir.

\footnotetext{
${ }^{5}$ A ação "[...] curtir é a opção simples, mas concretiza uma interação complexa, pois com apenas um click, o ator da publicação colhe benefícios tais como relacionados a: visibilidade; fortalecimento de laços; construção identitária; capital social e ethos compartilhado" (BOYD, 2011).
} 
Figura 2: Print Screen do Facebook

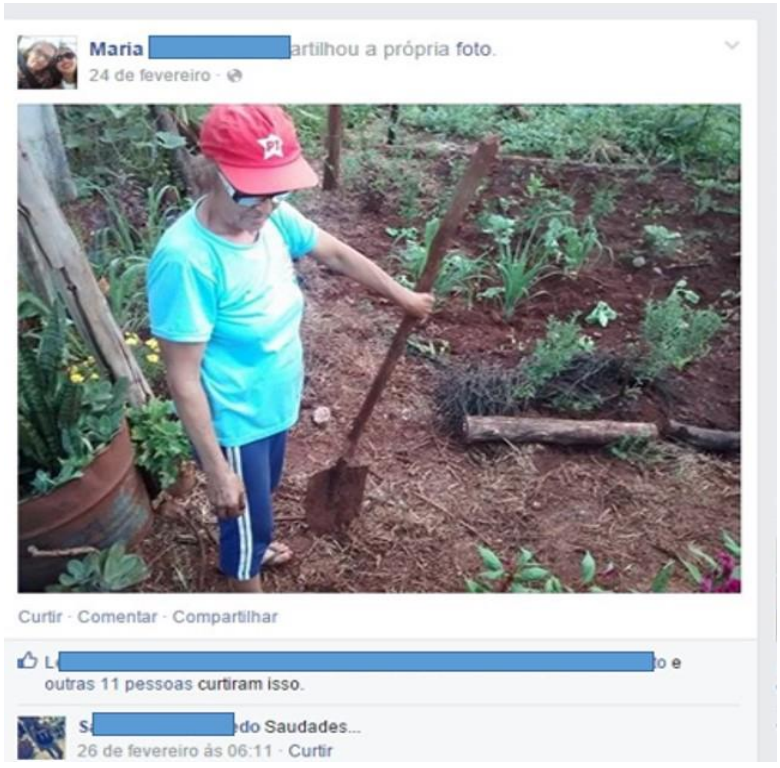

Fonte: Facebook, 2017.

Nota-se que as imagens anteriores e posterior apresentam como pano de fundo a terra (uma delas em um plano inclinado) e são marcadas pela luz do dia, caracterizadas também pelas matizes de cor, tanto no verde das árvores quanto no azul do céu e do vermelho da terra, o que destaca a paisagem, o solo produtivo, maquinários e o trabalho. Ainda é possível ver nas imagens uma ideia de imensidão, de profundidade, levando-nos a pensar na extensão de terra e, por consequência, na extensão do trabalho delas.

Figura 3: Print Screen do Facebook

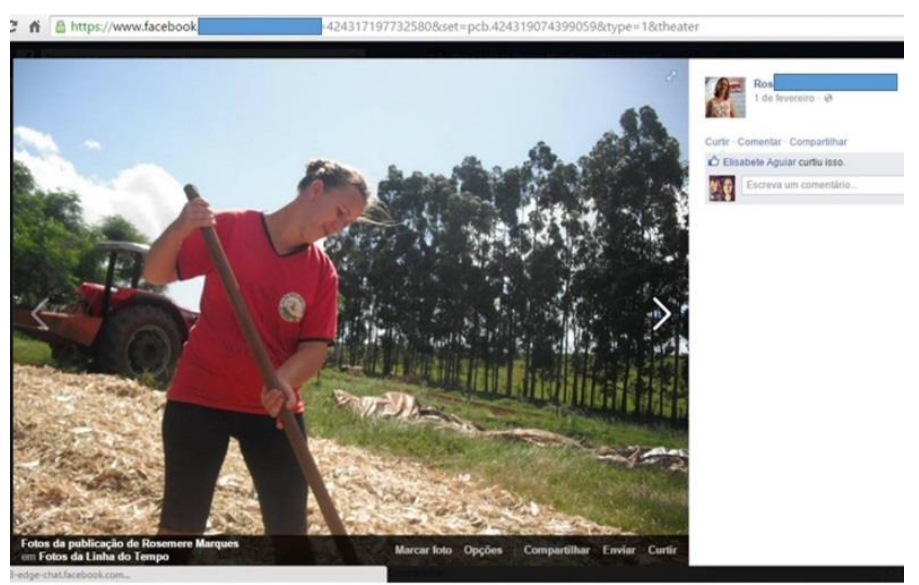

Fonte: Facebook, 2017.

Observa-se, nessas publicações, o protagonismo no trabalho com a terra (produção): a mulher adulta, de corpo inteiro, segurando a enxada e movimentando-a sobre a terra lamacenta entre o claro da silagem. Com isso, a figura enuncia um discurso do esforço do trabalho realizado 
por ela nessa produção conhecida como silagem. A silagem é um produto oriundo da conservação de forragens úmidas ou de grãos de cereais com alta umidade (grão úmido) por meio da fermentação em meio anaeróbico. Como é produzida com grãos úmidos (os grãos incham), é um trabalho relativamente pesado.

Entre os elementos que compõem publicações como essas, vemos o rosto da trabalhadora compenetrada na atividade, a expressão do esforço em seus braços e um apoio que lhe sustenta as mãos ao segurar a enxada e/ou a pá - uma visão do trabalho, tensionada pelos gestos do corpo. A constituição desse tipo de economia visual do corpo coligada às formas gestuais produz uma escritura do trabalho em execução, estabelecendo uma pragmática do visível, o manejo da terra e a força do trabalho delas. Essa é uma posição que parece sugerir o trabalho das mulheres como esteio, como base da produção. Ainda, a figura deixa-nos entrever que as mulheres têm força suficiente para estar à altura de tal trabalho. Essa postagem abre espaço para mostrar um agenciamento, em que as mulheres se deslocam do trabalho do interior da casa ao exterior, para o universo da produção agrícola, como visualizamos.

O enunciado da figura postada - "muito trabalho" - faz pensar no encadeamento de tarefas, em um ciclo que quase nunca termina, numa dupla jornada de trabalho. Como as mulheres afirmam nas entrevistas e é possível visualizar na publicação, “[...] o trabalho vai desde a plantação do milho até a produção da silagem, o trato dos animais, a ordenha das vacas, a venda do leite, e assim por diante" (ROSE, 28 anos). Como vemos nessas imagens, às mulheres, normalmente, cabe o trabalho com equipamentos como enxadas, foices, pás, que envolvem grande esforço físico, talvez justificando o enunciado "muito trabalho".

Outro fato que nos chama a atenção é que alguns equipamentos, como o trator e o carretão, normalmente são operados pelos homens. Quando perguntamos a uma das entrevistadas o porquê da escolha dessas publicações, ela disse: "[...] é uma forma de conhecerem meu trabalho" (ROSE, 28 anos). E ainda destacou "[...] muitas mulheres aqui produzem muito mais que os homens. Trabalham muito, preparam a terra [...] a mulherada aqui não tem tempo ruim; elas carregam para a frente a propriedade".

Outro elemento, como visto na Figura 1, é uma mulher-menina, já envolvida com o trabalho, o que nos faz refletir também sobre o fato de o meio rural abrigar uma porcentagem maior de trabalhadores infantis. Razões para tal que incluem desde a infraestrutura escolar geralmente mais fraca, que pode desencorajar a frequência à escola, além da maior facilidade de as crianças e adolescentes serem absorvidos em atividades informais e da prevalência de trabalhos agrícolas familiares que exigem menor qualificação. O fator cultural pode ser levado em consideração, pois mães que trabalharam quando crianças enxergam com maior naturalidade o trabalho infantil e são mais propensas a colocar as filhas para trabalhar.

As mulheres, historicamente vistas como guardiãs e transmissoras de valores familiares, na maioria das vezes são responsáveis por ensinar as crianças a trabalhar. O início precoce no trabalho se dá auxiliando os adultos nas tarefas domésticas, depois passando para o exterior da casa, ocupando-se de atividades com o trato dos animais e, ainda, a carpir, roçar, carregar pesos. Pode ser observado que a menina está sendo ensinada a fazer o mesmo trabalho que a mulher adulta.

É comum encontrarmos outros discursos desse grupo de mulheres pesquisadas, na rede social digital Facebook, tais como: "[...] bora carpir ${ }^{6}$; Mulher... vamos pegar na enxada, somos mulheres e pegamos no pesado". Quando questionadas, ouvimos que: "[...] se você vai ficar esperando só por ele, nunca vai para frente, e por isso que vai lá pega a sua enxada, um pouquinho

\footnotetext{
6 "Vamos embora?". Palavra usada para incentivar ou convidar alguém a ir a algum lugar ou fazer alguma atividade, sendo geralmente usada em pergunta.
} 
de esforço" (MARIA, 62 anos). Observa-se que, de um modo geral, essas mulheres têm orgulho de seu trabalho e dizem que "[...] têm muita força para enfrentar os desafios do trabalho". Entendemos que o conjunto dessas publicações ajudam a quebrar o silêncio de muitas mulheres mediante a criação de espaços de fala quando suas ações laborais são publicizadas.

De acordo com Siliprandi (2011), as mulheres rurais foram invisibilizadas como trabalhadoras com a terra. Para a autora (2011, p. 175), o trabalho das mulheres geralmente é " [...] considerado apenas uma ajuda dentro da família, enquanto o homem é considerado como o verdadeiro produtor rural". $\mathrm{Na}$ maioria das vezes, para as mulheres, os “[...] seus conhecimentos e experiências são menosprezados; a representação pública é outorgada ao homem, permanecendo as mulheres restritas ao mundo doméstico" (SILIPRANDI, 2011, p. 175). O trabalho no meio rural, ou melhor, a força feminina no trabalho rural permaneceu por muito tempo em silêncio, culminando num retardo do reconhecimento da profissão de produtora rural.

O silêncio das mulheres no campo foi/é normalizado, no sentido de falta de registros da historiografia que retratem a existência cotidiana e particular da vida "real". As mulheres, por muito tempo, foram invisíveis nas atividades rurais, na medida em que o processo do trabalho na terra se consolidou como masculino (PARISIUS, 1999). O trabalho produtivo da mulher não era (é) reconhecido como componente fundante, e sim como componente subliminar, como uma ajuda ao trabalhador principal, o homem. Desse modo, entendemos que essas publicações no Facebook ajudam na divulgação de um trabalho, até então, invisível ou pouco divulgado.

Observamos que. por meio das suas publicações, as mulheres mostram sua importância e o lugar que ocupam na produção agrícola e na transformação dos produtos em alimentos. Publicações como a que segue proliferam nas suas postagens e celebram o trabalho cotidiano que realizam.

Figura 4: Print Screen do Facebook

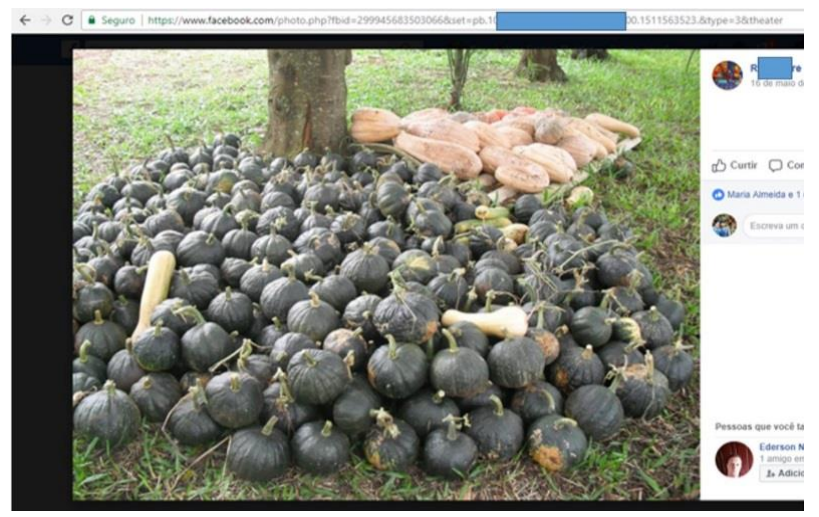

Fonte: Facebook, 2017.

Essa publicação retrata a abundância da colheita, no caso aqui, de morangas, resultado de muito trabalho, cuidado, envolvimento. Talvez tais publicações possam também ser um exercício exibicionista na direção de destacar a abundância da produção. Há um tipo de pacto nas redes digitais: ter uma boa imagem como primeiro passo de reconhecimento social. Dessa forma, as mulheres encontram uma estratégia de visibilidade ao mostrar sua produção na terra.

Um dos ambientes em que as mulheres brasileiras têm pouco reconhecimento é no setor produtivo agrícola, em que, quase sempre, estiveram rotuladas como coadjuvantes dentro do processo de produção e de gestão dos espaços rurais. Um exemplo da situação das mulheres do campo é a sua não-identificação como produtora rural, o que se reflete na desigualdade de 
distribuição dos benefícios trazidos pelas políticas públicas ao longo dos anos. O trabalho das mulheres na agricultura familiar, muitas vezes denominado ajuda, é intenso, pesado; entretanto, o acesso às políticas públicas fica, em grande parte, para o homem, tendo em vista que a Declaração de Aptidão ao Pronaf (DAP), por exemplo, é familiar e o titular geralmente é o homem.

As mulheres rurais estudadas, geralmente, quando são as responsáveis pela produção agrícola, optam pelo sistema agroecológico, respeitando e preservando os recursos naturais, bem como fazem o trabalho de seleção e de conservação de sementes. Para Cinelli (2012, p. 13), “[...] os atos de recuperar e produzir as sementes estão intimamente ligados à produção de alimentos saudáveis, relacionada com a valorização do trabalho da mulher e não só do homem, pois em grande medida o fazer feminino é desvalorizado”. Na concepção de Siliprandi (2011, p. 178):

A produção de alimentos voltada para o consumo interno, sem a dilapidação dos recursos naturais, pressupõe políticas de apoio à diversificação de cultivos, o monitoramento dos impactos ambientais das práticas agrícolas atuais, o estímulo a práticas conservacionistas com relação à biodiversidade e apoio aos circuitos locais de comercialização.

Nesse sentido, as publicações desse grupo de mulheres destacam a importância da diversificação da produção agrícola voltada para a subsistência, com excedente direcionado à comercialização. Este excedente, quando divulgado, dá às mulheres rurais reconhecimento da vida ordinária de seu cotidiano e das ações de seus trabalhos. Entendemos que a cultura midiática das redes sociais digitais, no caso, o Facebook, tem aberto espaço para uma tênue linha que demarca a visibilidade do trabalho das mulheres rurais, deslocando-as da histórica condição invisível. Estamos diante de um "novo" dispositivo (FOUCAULT, 2013) que, de modo sutil e não menos efetivo, corrobora a representação das mulheres rurais e divulga seu trabalho na terra na produção agrícola. Em presença, para os olhos de quem as vê, talvez estejam produzindo uma outra "memória".

As mulheres expõem suas ações laborais, suas posições de trabalhadoras, para apreciação pública - trata-se de um eu que se faz mediante a visibilidade, que recorre ao reconhecimento do Outro. Os comentários do Outro nas publicações "[...] atuam para confirmar a sua subjetividade, que só pode se construir [...] diante do olhar alheio" (SIBILIA, 2008, p. 148). No caso dessas publicações, há uma celebração da trabalhadora rural, com a qual um grande número de mulheres se identifica, o que pode ser observado nos discursos capturados nas entrevistas, quando relatam o número de comentários e curtidas que recebem. Há um compartilhamento de sentidos por meio dessas publicações. As ações das mulheres tornam-se visíveis: há "[...] uma subjetividade que se 'modela' para reconhecimento público, exibida no exercício de superação das próprias fraquezas" (TAYLOR, 2009, p. 74).

As publicações das 14 mulheres que acompanhamos parecem reafirmar, dar visibilidade, ao modelo da mulher que "trabalha pesado" na terra, da mulher produtiva, bem-sucedida em uma sociedade pautada pela competividade e pelo alto desempenho, como símbolos garantidores de reconhecimento (TAYLOR, 2009). A visibilidade, como condição da visão, ultrapassa e reconfigura a consciência objetiva do que é visto; materializa, ao mesmo tempo, a referencialidade palpável, guiada a partir de uma produção discursiva de si - das mulheres. Salientamos que essa visibilidade diz respeito a um processo - tanto de educação do olhar público, quanto de afirmação subjetiva das mulheres. Essas publicações na rede social digital Facebook parecem forjar uma estratégia de visibilidade das mulheres rurais e, de um modo particular, o reconhecimento de seu trabalho com e na terra.

Mesmo que essas publicações possam ser espontâneas, irrefletidas, inconscientes, entendemos que acabam inscrevendo uma realidade simbólica da trabalhadora rural, o que vinculamos com "novas politicidades", como destaca Rocha (2010). Consideramos que essas 
publicações podem ser um protesto, e acabam gestando um aparecer político do trabalho pesado com a terra, com a produção agrícola.

Entendemos que publicações como essas trazem para a cena pública as trabalhadoras rurais e possibilitam uma certa contraposição ao trabalho da mulher rural no âmbito privado - da casa. As publicações, ainda que visem a uma apreciação do Outro, propõem ao mesmo tempo um sentimento de ser agente criadora de seu "ser no mundo", elaborando outros olhares e outras narrativas de si (RAGO, 2013). Esse exercício, pela via das postagens online, permite a essas mulheres rurais que vocalizem suas ações. Entendemos que as publicações produzem demandas de reconhecimento que podem sedimentar novas relações éticas e outras memórias. Tomamos essas publicações como uma política da estética da existência (RAGO, 2013), entrelaçada com a produção de "novos sujeitos políticos", novas posições do ser mulher.

Há uma certa política da estética da existência que, por meio dessas publicações, reconfigura regimes de visibilidade, questionando algumas das velhas ordens discursivas. Para Rancière (2005), a política da estética consiste na elaboração do anônimo, do eu e do outro, do qual emerge o mundo do nós político. Isso, para o autor (2005), implica partilhar em palavras, imagens, modos, significados e sentidos, de maneira que "[...] outros enxerguem o 'território visualmente banalizado, o da margem" e assim o seja devolvido à "[...] potencialidade visível-existencial, a riqueza do vivível seja compartilhada" (RANCIÈRE, 2005, p. 65).

As publicações das mulheres rurais são tomadas aqui como um novo lugar de enunciação, de uma nova politicidade, sendo um dos modos de elas se ocuparem e darem sentidos ao espaço público, de construir uma cidadania cultural além da de direito. Após acompanharmos as publicações dessas mulheres, podemos dizer que, raramente, encontramos imagens de selfies, o que talvez nos ajude a pensar que essas mulheres mostram muito mais que seu corpo e/ou rosto. Elas publicam o seu cotidiano, o trabalho agrícola, as vivências sociais do meio rural. Observa-se um número muito maior de publicações que destacam o orgulho do trabalho que realizam quando afirmam e sinalizam "[...] temos muque e trabalhamos" (ROSANE, 42 anos).

Henriques e Dodebei (2013, p. 58) auxiliam-nos a pensar que "[...] as narrativas registradas nas redes sociais seriam mosaicos que possibilitam uma leitura da memória social do presente através das junções de seus vários fragmentos". Podemos dizer, assim, que as mulheres, ao publicarem e tornarem visível parte de suas vivências no meio rural, estariam externando suas impressões e leituras do seu dia a dia, registrando e marcando o tempo presente.

A memória, a partir das redes sociais virtuais, possibilita novos processos de memoração e rememoração, o que modifica, reconfigura o tempo presente por intermédio de uma memória que talvez nunca esteve tão viva e em permanente atualização (CUNHA, 2009). A rede social digital Facebook mantém em circulação o princípio ativo do registro: "[...] olhem o que estamos fazendo agora” (RENDEIRO, 2015, p. 87). Para Rendeiro (2015, p. 28), a rede social digital Facebook “"...] parece dar eco à vontade de preservar os instantes, as imagens e os restos que se somam na aceleração contemporânea, na ânsia de marcar a si mesmo e escapar do esquecimento".

\section{LONGE DE PALAVRAS FINAIS}

De acordo com as análises, as mulheres observadas nessa pesquisa, são de uma geração anterior ao surgimento da Internet e à comunicação mediada pelo computador e, ainda assim, mantêm uma rotina de publicações. Observamos, pelas publicações e entrevistas, um

\footnotetext{
${ }^{7}$ Muque, sinônimo de músculo desenvolvido, resultante de exercícios físicos constantes; o bíceps e o tríceps, que impulsionam ou sustentam a força dos membros superiores.
} 
engendramento de outras narrativas na direção da posição da mulher rural como aquela que trabalha pesado na terra e produz a riqueza na propriedade, criando assim visibilidades para as suas ações laborais, muito além do trabalho com a casa. Desse modo, tornam públicas as suas ações laborais.

$\mathrm{O}$ acesso à Internet e às redes sociais digitais, amplia a possibilita de exposição e de visibilidade das publicações compartilhadas, proporcionando uma existência-virtual, o que compreendemos como um fenômeno contemporâneo. Entendemos que essas publicações promovem experiências que reinventam as mulheres rurais na posição de trabalhadoras da/com a terra, produzindo um certo dissenso das antigas posições de ajuda de margem, de um trabalho de parcas contribuições. Isso talvez ajude a fissurar as lógicas subalternizantes na desconstrução do discurso patriarcal enraizado no Brasil, de um modelo apenas do homem provedor e do modelo de mulher doméstica. Elas, as mulheres, propõem alternativas de novas posições sociais ligadas ao trabalho em que ainda são pouco reconhecidas.

É no contexto rural brasileiro - historicamente caracterizado por oferecer pouco espaço de expressão para as mulheres, em que não eram estimuladas a argumentar e usar a palavra no espaço público, mas calar e obedecer — que observamos que essas 14 mulheres pesquisadas produzem fissuras, ao publicizarem de modo particular os seus trabalhos com a terra. As redes sociais digitais têm propiciado o registro de outras memórias, realizado pelas suas próprias histórias por meio de suas publicações. Tomamos a memória em uma perspectiva mais ampla, que se integra como um processo político. Esse grupo de mulheres rurais expressa, assim, diferenças em suas memórias - umas mais concretas, ligadas ao cotidiano, que as marcam, mostrando suas presenças ativas a partir de suas experiências. A utilização dessas publicações, portanto, permite trabalhar com esta memória diferenciada, que denominamos de memória do presente, porque traz informações sobre aspectos pouco conhecidos do meio rural a partir do que é vivido cotidianamente. Estar nas redes sociais digitais é ser "ouvido", é falar para audiência mais ampla que se encontra muito além do nosso alcance geográfico.

Este artigo serve para registrar que ainda nos resta muitos aspectos a conhecer sobre o cotidiano brasileiro das mulheres rurais. Apresentamos aqui alguns dos desdobramentos possíveis. Desafiamo-nos a apresentar uma memória de esperança que se caracterizaria pela perspectiva de mudança das posições das mulheres rurais como pessoas com direito a fala, que buscam marcar o tempo presente dando visibilidade às suas trajetórias / projeção / trabalho de um fazer que mantém seus laços produtivos com a terra. Temos muito o que conhecer, registrar e divulgar sobre os feitos das mulheres, de modo particular com as mulheres rurais, seus fazeres, suas lutas, suas estratégias de solidariedade e de enfrentamento, evitando que essas mulheres fiquem nos registros históricos como coadjuvantes.

\section{REFERÊNCIAS}

AMARAL, Adriana; NATAL, Geórgia; VIANA, Lucina. Netnografia como aporte metodológico da pesquisa digital. Cadernos da Escola de Comunicação, Curitiba, n. 6, 2008. Disponível em: http://revistaseletronicas.pucrs.br/ojs/index.php/famecos/article/view/4829/3687. Acesso em: 21 set. 2018.

BOYD, Danah. Social Networks Sites as Networked Publics: Affordances, Dynamics, and Implications. In: PAPACHARISSI, Zizi (org.). A networked self: identity, community, and culture on Social Network Sites. Nova Iorque: Routeledge, 2011.

CANDAU, Joël. Memória e identidade. São Paulo: Contexto, 2012. 
CARVALHO, Rejane. Transição democrática brasileira e padrão midiático publicitário da Política. Campinas: Pontes; Fortaleza: Universidade Federal do Ceará, 1999.

CINELLI, Catiane. Programa de sementes crioulas de hortaliças: experiência e identidades no Movimento de Mulheres Camponesas. 113 f. (Dissertação) Programa de Pós-Graduação em Educação nas Ciências (Mestrado em Educação nas Ciências), UNIJUÍ, Ijuí, 2012.

CUNHA, Mágda da. Conectados e distraídos: Corpos caminhantes e ação narrativa. Revista GHREBH, $\quad$ v. 2009.2 Disponível em: https://www.cisc.org.br/portal/jdownloads/Ghrebh/Ghrebh-\%2014/08_cunha.pdf. Acesso em 18 jul. 2017.

FACEBOOK. Disponível em: https://www.Facebook.com/. Acesso em: 15 jul. de 2017.

FISCHER, Rosa. Foucault e os meninos infames de Cidade de Deus. Revista Educação Especial. Biblioteca do Professor, São Paulo, jan. 2007. p. 56-65.

FOUCAULT, Michel. A verdade e as formas jurídicas. 4. ed. Rio de Janeiro: Nau, 2013.

FOUCAULT, Michel. A ordem do discurso. São Paulo: Loyola, 2010.

HALBWACHS, Maurice. A memória coletiva. Trad. de Beatriz Sidou. São Paulo: Centauro, 2006.

HENRIQUES, Rosali; DODEBEI, Vera. A virtualização da memória no Facebook. CES Revista, Juiz de Fora, v. 27, n. 1, dez./jan. 2013. p. 257-273.

JENKINS, Henry. Cultura da convergência: a colisão entre os velhos e novos meios de comunicação. [Tradução Susana Alexandria]. 2. ed. São Paulo: Aleph, 2009.

LE GOFF, Jacques. História e memória. Campinas, São Paulo: Ed. Unicamp, 2003.

LIPOVETSKY, Gilles; SERROY, Jean. A cultura mundo: resposta a uma sociedade desorientada. Lisboa: Edições 70, 2010.

MIGUEL Ana de; BOIX, Montserrat. Os gêneros da rede: os ciberfeminismos. In: NATANSOHN, Graciela (org.). Internet em código feminino: teorias e práticas. Buenos Aires: La Crujia, 2013.

PARISIUS, Corneia. A luta que me fez crescer. In: PARISIUS, Corneia (org.). Recife: DED; Bagaço, 1999.

PEREIRA, Vinicius. Compreendendo os M.E.D.I.A. - Mídias, Entretenimento, Design, Informação e Artes: as extensões da comunicação. Compós, Goiana, 2016, p. 18.

PERROT, Michelle. As mulheres e os silêncios da História. Bauru, São Paulo: EDUSC, 2005.

ORGANIZAÇÃO DAS NAÇÕES UNIDAS. A importância das mulheres rurais no desenvolvimento sustentável do futuro. Disponível em: https://nacoesunidas.org/artigo-a-importancia-das-mulheresrurais-no-desenvolvimento-sustentavel-do-futuro/. Acesso em: 23 out. 2018.

RAGO, Margareth. A aventura de contar-se: feminismos, escrita de si e invenções de subjetividade. Campinas: Ed. Unicamp, 2013.

RANCIÈRE, Jacques. A partilha do sensivel: estética e política. São Paulo: Ed. 34, 2005.

RENDEIRO, Márcia. As arestas sociais do Facebook: fotografias, coleções, memória e melancolia. 189 f. (Tese) Programa de Pós-Graduação em Memória Social. (Doutorado em Memória Social), Universidade Federal do Estado do Rio de Janeiro, Rio de Janeiro, 2015.

RECUERO, Raquel. Redes sociais na Internet. Porto Alegre: Sulina, 2009.

ROCHA, Rose. Políticas de visibilidade como fatos de afecção: que ética para as visualidades? Revista FAMECOS (online), v. 17, p. 6264, 2010. Disponível em: 
http://revistaseletronicas.pucrs.br/ojs/index.php/revistafamecos/article/view/8187. Acesso em: 18 jul. 2017.

SALES, Celecina. Mulheres rurais: tecendo novas relações e reconhecendo direitos. Revista Estudos Feministas, Florianópolis, v. 15, n. 2, p. 437-443, 2007. Disponível em: https://periodicos.ufsc.br/index.php/ref/article/view/S0104-026X2007000200010. Acesso em: 21 set. 2018.

SCHWENGBER, Maria S. V. O uso metodológico da imagem. In: MEYER, D. E.; PARAÍSO, M. A. (org.). Metodologias de pesquisas pós-críticas em educação. Belo Horizonte: Mazza, 2012. p. 261-279.

SIBILIA, Paula. O show do eu: a intimidade como espetáculo. Rio de Janeiro: Nova Fronteira, 2008.

SILIPRANDI, Emma. Mulheres agricultoras no Brasil: sujeitos políticos na luta por soberania e segurança alimentar. Pensamiento Iberoamericano, n. 9, 2011.

SOARES, Carmem. Memórias da natureza: Georges Hébert e a educação do corpo. Revista Digital, Buenos Aires, Ano 8, n. 55, Diciembre de 2002.

TAYLOR, Charles. A ética da autenticidade. Lisboa: Edições 70, 2009.

VIRILIO, Paul. O paradoxo da memória do presente na era cibernética. In: CASALEGNO, Federico. Memória cotidiana: comunidades e comunicação na era das redes. Porto Alegre: Sulina, 2006.

\section{Informações das autoras}

Naira Leticia Giongo Mendes Pinheiro

Doutoranda em Educação nas Ciências do Programa de Pós-graduação em Educação nas Ciências da Universidade Regional do Noroeste do Estado do Rio Grande do Sul

E-mail: nairaleticiagmendespinheiro@gmail.com

ORCID: https://orcid.org/0000-0001-7920-1478

Link Lattes: http://lattes.cnpq.br/4843062597611019

Maria Simone Vione Schwengber

Doutora em Educação. Professora do Programa de Pós-graduação em Educação nas Ciências da Universidade Regional do Noroeste do Estado do Rio Grande do Sul

E-mail:simone@unijui.edu.br

ORCID: https://orcid.org/0000-0002-3583-1408

Link Lattes: http://lattes.cnpq.br/3254736616560965 